\title{
PEMASARAN TERNAK DOMBA DI PASAR HEWAN PALASARI KABUPATEN INDRAMAYU
}

\author{
Broto Wibow, S. Rusdiana dan U. Adiati \\ Balai Penelitian Ternak Ciawi \\ s.rusdiana20@gmail.com
}

\begin{abstract}
ABSTRAK
Penelitian dilakukan di Pasar hewan Palasari Indramau Jawa Barat, penentuan data dilakukan dengan metoda survey lapang dipasar hewan, pengambilan data dilakukan melalui wawancara terhadap 10 pedagang kecil, 10 pedagang besar, 10 calo ternak domba dan konsumen ternak domba, data primer dan data skunder dianalisis secara diskriptif dan kuantitatif. Tujuan tulisan ini adalah untuk mengetahui rantai pemasaran ternak domba di pasar hewan Palasari Indramayu. Hasil Penelitian rantai pemasaran ternak domba mempunyai 3 (tiga) mata rantai hingga pada konsumen akhir, pada masing-masing mata rantai memiliki margin pemasaran tersendiri, yaitu rantai pemasaran I, II dan III, masing-masing rantai pemasaran menentukan nilai share, dengan keuntungan yang berbeda, diperoleh rantai pemasaran I pedagnag kecil nilai share sekitar $2 \% /$ ekor, rantai pemasaran II pedagang besar nilai share sekitar $2 \% /$ kkor dan rantai pemasaran III para calo nilai share sekitar 1,5\%/ekor. Rantai pemasaran I pedagang kecil nilai jual ternak domba jantan dewasa awal sekitar Rp 2.300.000/ ekor dan nilai jual akhir pada konsumen sekitar Rp 2.476.815/ ekor, dengan peningkatan nilai harga sekitar Rp 128.813.38/ekor, rantai pemasaran II pedagang besar nilai jual ternak domba jantan dewasa awal sekitar Rp 2.392.920/ekor dan nilai jual akhir pada konsumen sekitar Rp 2.428.813,8/ekor, dengan peningkatan nilai harga sekitar Rp 128.813.38/ekor dan rantai pemasaran III calo nilai jual ternak domba jantan dewasa awal sekitar Rp 2.346.000/ekor dan nilai jual akhir pada konsumen sekitar Rp 2.428.813,8/ekor, dengan peningkatan nilai harga sekitar Rp 35.893,8/ekor.
\end{abstract}

Kata kunci: Pasar Ternak Domba, Palasari, Indramayu

\section{LAMB LIVESTOCK MARKETING IN THE MARKET OF ANIMAL PALASARI DISTRICT INDRAMAYU}

\section{ABSTRACT}

The study was conducted at the market animal Palasari Indramayu, West Java, the determination of the data is done by the method of field survey on the market of animals, data retrieval is done through interviews with 10 small merchants, 10 wholesalers, 10 brokers sheep and consumers sheep, primary data and secondary data analyzed diskriptif and quantitative. The purpose of this paper is to investigate the marketing chain of sheep at the animal market research Indramayu. The results Palasari marketing chain of sheep has 3 (three) chain until the end consumer, in each chain has its own marketing margin, which is the marketing chain I, II and III, respectively the marketing chain determines the value of the shares, with a distinct advantage, obtained marketing chain I pedagnag small value share of around $2 \% /$ head, the marketing chain II wholesalers value share of around $2 \% /$ head and marketing chain III brokers value share of about $1.5 \% /$ head. Marketing chain of small traders selling points early adult male sheep around $R p$ 2.300.000/head and the value of the final sale 


\section{Agriekonomika, ISSN 2301-9948 \\ e ISSN 2407-6260 \\ Volume 5, Nomor 1}

to the consumer about Rp 2.476.815/head, with the increase in the value price of about Rp 128.813.38/head, the marketing chain II wholesalers selling points early adult male sheep around $R p$ 2.392.920/head and the value final sale to the consumer about Rp 2.428.813,8/ head, with the increase in the value price of about Rp 128.813.38/head and marketing chain III touts selling points early adult male sheep around $R p$ 2.346.000/head and the value of the final sale to the consumer about Rp 2.428.813,8/head, the value price with increase in of about, Rp 35.893.8/ head.

\section{Keywords: Cattle Market Sheep, Palasari, Indramayu}

\section{PENDAHULUAN}

Pemasaran merupakan muara akhir dari suatu aktivitas produksi, untuk memperoleh nilai harga barang produksi guna melanjutkan usaha dikemudian hari dan menciptakan kesejahtreaan pengguna. Pasar dapat berupa suatu lokasi dimana terjadi transaksi dalam rangka pemindahan hak dari sutu pihak kepada pihak lainnya yang memanfaatkan alat tukar berupa uang yang diperlukan peternak pada berbagai aspek kehidupannya. Kegiatan pemasaran ternak dapat berlangsung pada berbagai lokasi, yaitu di lokasi kandang dipeternak maupun di lokasi pasar Hewan yang telah ditentukan oleh pemerintah daerah. Pasar hewan Palasari di Indramayu, hanya ada dua jenis ternak yang dipasarkan yaitu ternak domba dan kambing.

Rantai pemasaran yang panjang akan menyebabkan kerugian, baik bagi pedagang atau perodusen maupun bagi konsumen, karena konsumen akan terbebani dengan beban biaya pemasaran, untuk membayar harga yang tinggi. Menurut Elizabeth, dkk (2011), bahwa dengan adanya lembaga pemasaran dapat membantu pemindahan suatu produk, maka akan dapat diketahui berapa margin yang diperoleh pada setiap lembaga pemasaran yang memidahkan produk tersebut. Menurut Rusdiana dan Priyanto (2008), bahwa usaha peternakan domba dan kambing pada dasarnya merupakan kegiatan sampingan bagi peternak di perdesaan, dimana hasil produksinya sepenuhnya di arahkan ke pasar hewan, dan jarang sekali ditemui bahwa peternak langsung mengkonsumsi sendiri hasil ternak dalam pemeliharaan atau hasil dibudidaya sendiri.

Menurut Abubakar (2002), bahwa, margin pemasaran dapat didefinisikan menjadi dua cara sebagai margin pemasaran, yang merupakan perbedaan antara harga yang dibayarkan oleh konsumen dengan harga yang diterima oleh produsen. Menurut Girei, dkk (2013), dan Hangara, dkk (2012), dan Koesmara, dkk (2013), bahwa pemasaran perlu didukung oleh kelembagaan seperti adanya koperasi, gunanya untuk menyebarkan informasi antar peternak, dan disamping itu perlu adanya kelompok ternak untuk mendapatkan penyuluhan tentang pentingnya manajerial dan teknis dalam pemasaran. Sedangkan menurut Emhar, dkk (2014), bahwa margin pemasaran merupakan bagian dari semua biaya yang dibayarkan dan pendapatan yang diterima oleh setiap mata rantai pemasaran, yang terlibat dalam proses rantai pasok.

Pemasaran suatu produk dari produsen ke konsumen akan melibatkan beberapa badan atau perorangan mulai dari petani (produsen), perantara (blantik, pedagang pengepul, jagal, calo ternak) dan diakhiri konsumen. Dalam proses pemasaran maka masing- masing rantai pemasaran mempunyai peran dan fungsi tersendiri. Tujuan tulisan ini adalah untuk mengetahui rantai pemasaran ternak domba di pasar hewan Palasari Kabupaten Indramayu. 


\section{METODE PENELITIAN}

Penelitian dilakukan di Pasar hewan Palasari Indramayu, Provinsi Jawa Barat, dengan menggunakan metoda survey lapang dipasar hewan, pengambilan data dilakukan melalui wawancara terhadap 10 pedagang kecil atau sedang, 10 pedagang besar, 5 calo dan beberapa konsumen ternak domba, informasi data yang dimaksudkan meliputi jumlah ternak domba di pasar hewan, harga jual ternak domba, jumah ternak domba yang terjual, dan harga lepas pada calo. Data sekunder diambil dari berbagai hasil penelitian dan dari Dinas setempat, data yang diperoleh dianalisis secara diskriptif dan kuantitatif sesuai data yang diperoleh.

\section{Analisis Data}

Biaya pedagang ternak domba baik untuk pedagang besar dan pedagang kecil di pasar ternak, untuk melakukan aktivitas jual beli ternak domba meliputi lima komponen yaitu: biaya pengangkutan, biaya penyimpanan ternak sebelum dibawa kepasar ternak, biaya tenaga kerja dan biaya resiko usaha. Diantara komponen biaya tersebut, maka biaya pengangkutan biasanya paling besar karena ternak domba pada umumnya bersifat kamba (voluminous). Menurut Ramadhan (2009), dan Hangara, dkk (2012), mendefinisikan margin pemasaran merupakan perbedaan harga yang akan ditawarkan dan harga yang akan dibayar oleh konsumen.

Dengan kata lain margin pemasaran merupakan selisih antara harga di tingkat konsumen dengan harga di tingkat peternak produsen dengan formula sebagai berikut:

$M P=P r-P f$

Dimana Mp adalah margin pemasaran (ternak domba), Pr adalah harga konsumen (ternak domba), dan Pf adalah harga produsen (ternak domba).

\section{HASIL DAN PEMBAHASAN \\ Keadaan Umum Wilayah Penelitian}

Kecamatan Bangodua Kabupaten Indramayu mempunyai ketinggian sekitar $\leq 10 \mathrm{dpl}$, dengan topografi datar atau landay, curah hujan mencapai 188 $\mathrm{mm} /$ th dengan suhu rata-rata sekitar $30^{\circ} \mathrm{C}$, luas wilayah Kecamatan Bangodua sekitar 3.554 ha. Potensi sumber daya alam yang ada meliputi luas kawasan yang terbagi dari lahan persawahan, tegal, dan pekarangan digunakan sebagai pemukiman penduduk, selain sebagai pemukiman tanah pekarangan juga digunakan masyarakat sekitar sebagai penunjang sektor perekonomian termasuk didalamnya sektor pertanian dan peternakan (usaha ternak domba) Kecamatan Bangodua terbagi menjadi atas 7 desa, (Statistik Peternakan Kabupaten Indramayu, 2014) .

Pasar Hewan di Kabupaten Indramayu terdiri dari 5 lokasi, yaitu;

a) Pasar Hewan Kedokan, Desa Kedokan, Kecamatan Kedokan hari pasar (Senin dan Jum'at)

b) Pasar Hewan Jati Barang, Kecamatan Jati Barang, hari pasar (Minggu dan Rabu)

c) Pasar Hewan Bondan, hari pasar (Selasa)

d) Pasar Hewan Kertasemaya, hari pasar (Kemis)

e) Pasar Hewan Tukdana, hari pasar (Sabtu). 


\section{e ISSN 2407-6260 \\ Volume 5, Nomor 1}

Ketersediaan pasar hewan dalam satu wilayah akan memberikan peluang bagi para pedagang ternak domba untuk melakukan kegiatan perdagannya, sehingga tidak menutup kemungkinan bahwa seseorang pedagang hewan akan menjual ternak yang dimiliki dari satu pasar ke pasar yang lainnya. Pasar hewan Palasari, Indramayu merupakan salah satu pasar hewan lingkup Kabupaten Indramayu. Pada umumnya kegiatan pasar hewan berdasarkan hari pasaran perhitungan jawa yaitu Wage.

Didalam perhitungan kalender jawa terdapat 5 perhitungan yaitu (Pon, Wage , Kliwon, Legi dan Paing), sehingga dalam 1 (satu) minggu untuk sebuah pasar hewan dapat melaksanakan kegiatan pemasaran sebanyak 2 (dua) kali, hal ini disebabkan menurut perhitungan kalender masehi yaitu (Senin, Selasa, Rabu, Kamis , Jum'at, Sabtu dan Minggu) maka jika pasaran tersebut jatuh pada hari Senen Wage maka untuk selanjutnya akan terulang kembali pada hari Sabtu Wage, demikian seterusnya, sehingga perhitungan menurut hari akan berubah-ubah. Namun ketentuan perhitungan Wage menjadi patokan sebagai aktivitas kegiatan pasar hewan yang bersangkutan.

\section{Karakteristik Responden Pedagang Ternak Domba}

Hasil survey lapang di pasar hewan Palasari Indramayu menunjukkan bahwa, karakteristik pedagang kecil, pedagang sedang, pedagang besar dan para calo ternak domba dengan rata-rata pendidikan responden adalah SD sekitar 70\%, SMP sekitar 23,33\% dan SMA sekitar 6,67\% dan rata-rata umur responden sekitar 46,2 tahun, pengalaman berdagang ternak domba rata-rata sekitar 21,2 tahun. Walaupun responeden pedagang kecil, pedagang besar dan calo diidentifikasikan berpendidikan cukup rendah tamatan SD, namun dengan umur responden yang masih produktif dan pengalaman dagang ternak domba yang cukup lama, maka kegiatan usaha pemasaran ternak domba di pasar hewan Palasari Indramayu tetap berjalan dengan lancer sesuai dengan aturan Pemda setempat.

Pasar hewan Palasarai Indramayu buka setiap hari jumat dan hari Sabtu, untuk mengefisiensikan suatu usaha ternak domba di pasar hewan, maka pedagang kecil, pedagang sedang dan pedagang besar selalu melibatkan suatu sistem penjualan yang sedikitnya 3 (tiga) pelaku utama yaitu: produsen, konsumen dan para calo ternak, dengan adanya 3 (tiga) pelaku tersebut maka kegiatan pasar hewan berjalan dengan baik.

\section{Diskripsi Calo Ternak Domba di Pasar Hewan}

Hubungan antara produsen dan konsumen ternak domba dijembatani oleh pelaku pemasaran atau calo ternak domba di pasar hewan yang mempertemukan dua sistem pasar, antara pedagang dan pembeli. Kepercayaan pedagang kepada calo sudah berjalan cukup lama, walaupun tidak ada ikatan surat perjanjian, tetapi kegiatan tersebut sudah tradisi setempat dan kepercayaan yang sudah menjalin keakraban dengan penduduk sekitar pasar hewan Palasari Indramayu. Kewenangan para calo ternak domba ada keterbatasan untuk menaikan dan menurunkan harga jual ternak domba, yang sudah dinilai oleh pedagang besar dan pedagang kecil, dapat dinaikan sekitar 1$1,5 \%$ dari nilai jual ternak domba yang diberikan oleh pedagang ternak domba.

Apabila konsumen meminta turun harga, maka calo tidak bisa untuk menentukan nilai jual ternak domba yang ditawarkannya, tetapi calo meminta ijin kembali kepada pedagang besar dan pedagang kecil, bahwa konsumen tidak beranai untuk memebayar sebesar harga yang ditawarkan oleh calo, setelah calo 
dapat ijin dari pedagang, bahwa harga yang diinginkan oleh konsumen dan sanggup untuk membayarnya, maka ternak domba dilepas dengan harga jual dari pedagang sebagai penentu harga awal.

\section{Fluktuasi Harga Ternak Domba di Pasar Hewan}

Fluktuasi nilai jual dan beli harga ternak domba dipasar hewan Palasari Indramayu, selau berubah setiap saat, naik dan turunnya harga jual dan beli erak domba merupakan salah satu isu sentral yang sering muncul di pasar hewan Palasarai. Kondisi pasar hewan kurang tertata rapi, dan belum ditempatkan pada areal yang khusus untuk pasar hewan, masih di lokasi pinggiran jalan, hal ini disebabkan oleh berbagai faktor diantaranya adalah:

a. Faktor waktu, yaitu menjelang pada hari raya besar seperti Idul Adha atau tahun baru Islam, perekonomian dimasyarakat sanget meningkat tajam, kebutuhan konsumen terhadap ternak domba jantan banyak dan dapat terpenuhi.

b. Faktor barang (kondisi ternak): nilai jual ternak domba sesuai dengan kondisi ternak domba dan keinginan konsumen, jumlah ternak di pasar hewan sesuai dengan jumlah konsumen ternak, karena konsumen banyak pilihan untuk memilih ternak domba baik sebagai bibit, daging dan lainnya, pelayanan pedagang besar, sedang maupun pedagang kecil dan calo sangat prima terhadap konsumen sehingga produsen dan konsumen terkesan penuh keakraban.

c. Jenis kelamin dan nilai jual harga ternak domba jantan yang berumur sekitar 1,2 tahun dan berat badan sekitar $30 \mathrm{~kg}$, dengan harga taksiran sekitar Rp.2.200.000/ ekor, dan sebaliknya bila sesudah hari Idul Adha, maka harga ternak domba jantan dewasa menajadi sekitar 2.000.000/ekor Sesuai dengan hasil penelitian Elizabeth, dkk (2011), bahwa harga jual ternak kambing dan domba tergantung besar kecilnya ternak dan kebutuhan konsumen.

\section{Rantai Pemasaran dan Nilai Jual Ternak Domba}

Coetzee, dkk (2005), menyatakan bahwa rantai pemasaran merupakan saluran pemasaran dari produsen ke konsumen untuk memenuhi kebutuhan pangan sehari-hari. Pedagang ternak domba di pasar hewan Palasari Indramayu telah memperhitungkan semua biaya yang telah dikeluaran, dan kemudian nilai harga jual ternak domba dapat ditentukan oleh para pedagang kecil, sedang da besar, sehingga pedagang mampu mengetahui jumlah keungan yang diinginkan. Alur pemasaran domba dan kambing didalam pasar Hewan Palasari Indramayu, secara umum alur pemasaran ternak domba di dalam pasar dapat dirangkai sebagai berikut:

a. Pedagang Desa menjual kepada Pedagang kecil atau pengumpul (melalui blantik).

b. Pedagang Desa menjual kepada pedagang Besar atau pengumpu (melalui blantik).

c. Pedagang Pengumpul/pedagang Kecil kepada pemotong Hewan atau pedagang kepercayaan tukang sate.

d. Pedagang Pengumpul atau pedagang Kecil kepada Pedagang besar atau pedagang pengumpul Besar (melalui blantik, dan pedagang kepercayaan pedagang besar). 


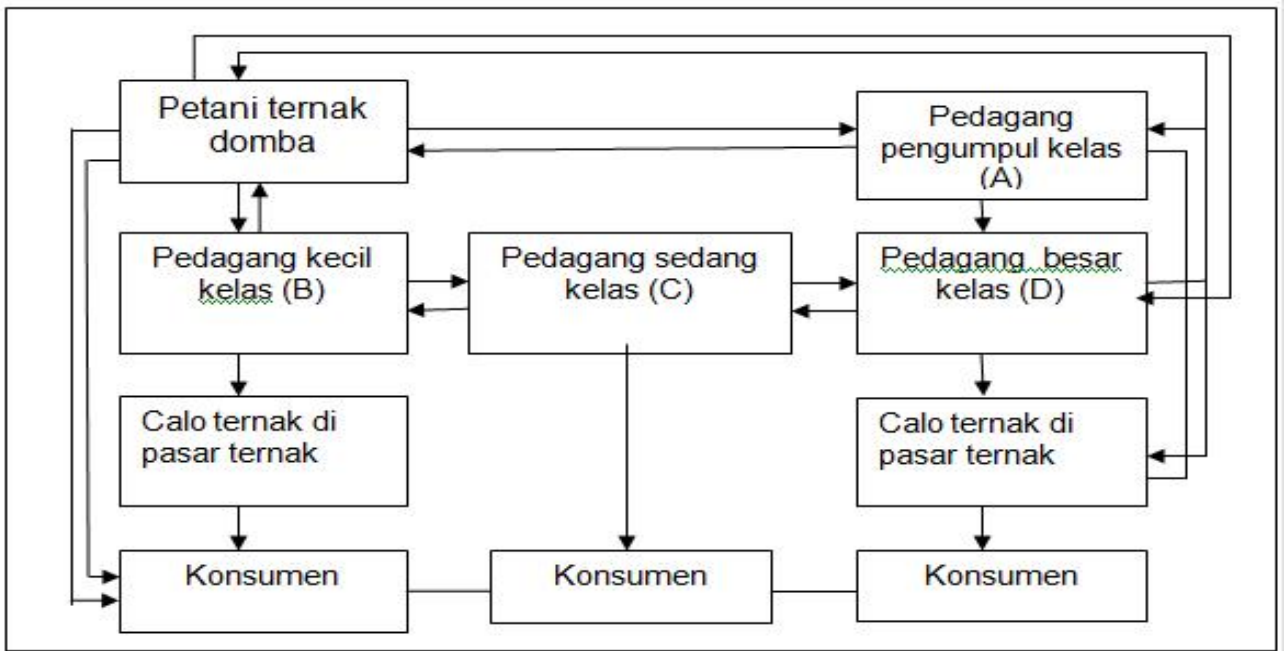

Sumber: Data Primer Diolah, 2015

\section{Gambar 1 \\ Rantai Pemasaran Ternak Domba di Pasar Hewan Palasari Indramayu 2015}

Pada Gambar 1, Rantai pemasaran ternak domba di Pasar hewan Palasari Indramayu. Peternak dapat menjual ke pedagang pengumpul, pedagang kecil dapat menjual ke pedagang besar, pedagang kecil dapat menjual ke pedagang besar, dapat mempercayakan untuk menjualkan ternak domba kepada para calo yang ada di pasar hewan. Pada akhirnya semua kegiatan pemasran ternak domba sampai ke konsumen, rantai pemasaran dapat menentukan nilai harga jual ternak domba pada posisi masing-masing marjin. Nilai jual ternak dombaditentukan oleh banyaknya biaya yang dikeluarkan diantaranya untuk pakan, tenaga kerja dan lainnya, dari setiap pendapatan terdapat jumah biaya yang harus dikeluarkan oleh setiap pedagang pengumpul, pedagnag kecil, pedagang sedang dan pedagang besar, terkecuali para calo ternak domba disekitar lingkungan pasar hewan Palasari Indramayu.

\section{Diskripsi Pedagang Ternak Domba}

Pedagang ternak yang melakukan aktivitas perdagangan dapat dikategorikan menjadi:

a) Pedagang pengumpul atau pedagang blantik desa (pedagang keliling) kelas $A$, yaitu pedagang ternak domba yang membeli dari peternak untuk selanjutnya dibawa ke pasar hewan sebagai barang dagangannya. Pedagang ini mempunyai skala penjualan yang rendah yaitu sekitar 2-3 ekor, demikian pula alat pengangkunya juga sederhana yaitu kendaraan roda 2 baik dengan tenaga mesin (motor) maupun tenaga manusia (sepeda ayuh).

b) Pedagang ternak domba pedagang kecil kelas B yaitu pedagang yang menjajakan maupun membeli ternak domba di peternak sekitar 5-10 ekor, sedangkan alat yang digunakan transpotasi menyewa mobil atau motor, setelah melakukan pemasaran yang dimulai pada jam 7 pagi hingga jam 11 siang, dan selanjutnya pedgang mencari lagi ternak domba ke 
berbagai desa untuk menemui peternak dalam rangka pembelian ternak, kegiatan ini dilakukan mulai jam 13 hingga jam 17 sore.

c) Pedagang kelas sedang kelas $\mathrm{C}$, yaitu pedagang yang menjajakan maupun membeli ternak didalam pasar hewan, pedagang ini mempunyai skala perdagangan antara 10-20 ekor, sedangkan alat transportasi berupa kendaraan bermesin roda 4 . Pada umumnya pedang ini membeli ternak didalam pasar untuk selanjutnya dijual lagi ke pasar hewan lainnya pada kegiatan pasar yang berbeda.

d) Pedagang besar kelas $D$, yaitu pedagang yang menjajakan dan membeli ternak didalam pasar untuk selanjutnya dijual keluar Daerah (diluar Kabupaten atau Propinsi), pedagang ini menggunakan alat transportasi kendaraan bermesin roda 4 , dengan kemampuan pengangkutan lebih dari 40 ekor.

e) Blantik (Calo) pasar, yaitu personil yang menjual ternak dari pedagang Desa atau pedagang pengumpul kecil untuk dijajakan kepada calon pembeli (pedang pengumpul kecil maupun pedagang pengumpul besar). Blantik bermodal pengetahuan dalam penawaran dalam penjualan.

f) Hampir seluruh transaksi melalui jalur blantik. Jika sudah didalam aktivitas kegiatan pemasaran maka pedagang desa pun dapat berperan sebagai blantik.

Untuk mengetahui nilai shere dari masing-masing rantai pemasaran I,II,III dan nilai harga jual ternak domba di pasar hewan Palasari terlihat pada Tabel 1.

\section{Tabel 1}

Nilai Share Masing-Masing Rantai Pemasaran I, II dan III pada Ternak Domba

\begin{tabular}{|c|c|c|c|c|}
\hline Jenis ternak & $\begin{array}{l}\text { Pedagang } \\
\text { Kecil/sedang } \\
(\mathrm{Rp})\end{array}$ & $\begin{array}{l}\text { Calo harga } \\
\text { (Rp./\%) }\end{array}$ & $\begin{array}{c}\text { Pedagang } \\
\text { besar harga } \\
(\mathrm{Rp} / \%)\end{array}$ & $\begin{array}{c}\text { Konsumen } \\
\text { Harga (Rp/\%) }\end{array}$ \\
\hline \multicolumn{5}{|c|}{ Rantai Pemasaran I } \\
\hline $\begin{array}{l}\text { Jantan } \\
\text { dewasa }\end{array}$ & 2.300 .00 & $\begin{array}{l}2,346.000 \\
(46.000)(2 \%)\end{array}$ & $\begin{array}{l}2.392 .920 \\
(46.920)(2 \%)\end{array}$ & $\begin{array}{l}2.428 .813,8 \\
35.893(1,5 \%)\end{array}$ \\
\hline Betina dewasa & 900.000 & $\begin{array}{l}922.500 \\
22.500(2,5 \%)\end{array}$ & $\begin{array}{l}940.950 \\
18.450(2 \%)\end{array}$ & $\begin{array}{l}955.065 \\
14.144,251,5 \%\end{array}$ \\
\hline \multicolumn{5}{|c|}{ Rantai Pemasaran II } \\
\hline $\begin{array}{l}\text { Jantan } \\
\text { dewasa }\end{array}$ & 2.300 .00 & $\begin{array}{l}2,346.000 \\
(46.000)(2 \%)\end{array}$ & - & $\begin{array}{l}2.428 .813,8 \\
128.813 .38 \\
(5,5 \%)\end{array}$ \\
\hline Betina dewasa & 900.000 & $\begin{array}{l}922.500 \\
22.500(2,5 \%)\end{array}$ & - & $\begin{array}{l}955.065 \\
40.950(3,5 \%)\end{array}$ \\
\hline \multicolumn{5}{|c|}{ Rantai Pemasaran III } \\
\hline $\begin{array}{l}\text { Jantan } \\
\text { dewasa }\end{array}$ & 2.300 .00 & $\begin{array}{l}2,346.000 \\
46.000(2 \%)\end{array}$ & - & $\begin{array}{l}2.428 .813,8 \\
35.893(1,5 \%)\end{array}$ \\
\hline Betina dewasa & 900.000 & - & - & $\begin{array}{l}955.065 \\
55.094,25(6 \%)\end{array}$ \\
\hline
\end{tabular}

Sumber: Data Primer Diolah, 2015

Tabel 1, Menunjukkan bahwa rantai pemasaran I pedagang kecil nilai jual ternak domba jantan dewasa awal sekitar Rp 2.300.000/ekor dan nilai jual akhir pada konsumen sekitar $\mathrm{Rp} 2.476 .815 /$ ekor, dengan peningkatan nilai harga sekitar Rp128.813.38/ekor, rantai pemasaran II pedagang besar nilai jual ternak domba jantan dewasa awal sekitar Rp 2.392.920/ekor dan nilai jual akhir pada 


\section{Agriekonomika, ISSN 2301-9948

konsumen sekitar Rp 2.428.813,8/ekor, dengan peningkatan nilai harga sekitar Rp 128.813.38/ekor dan rantai pemasaran III calo nilai jual ternak domba jantan dewasa awal sekitar Rp 2,346.000/ekor dan nilai jual akhir pada konsumen sekitar Rp 2.428.813,8/ekor, peningkatan nilai harga sekitar Rp 35.893,8/ekor.

Harga beli ternak domba induk jantan dewasa di tingkat pedagang kecil Rp 2.300.000 /ekor harga jual di pasar sekitar Rp 2.428.813,8/ekor, pedagang kecil dan pedagang besar memperhitungkan biaya transportasi dan biaya tenaga kerja dan pakan, besarnya marjin pemasaran domba secara keseluruhan mulai dari pedagang kecil hingga konsumen akhir adalah $\mathrm{Rp} 2.428 .813,8$ Rp.2.300.000=Rp.128.813.38/ekor pada ternak jantan atau share pemasaran sebesar Rp 2.428.813,8/Rp 2.300.000 x 100\% = 1.1\%.

Rantai pemasaran I, II dan III dari masing-masing rantai menentukan nilai sharenya dengan keuntungan yang berbeda, diperoleh rantai pemasaran I pedagnag kecil nilai share sekitar $2 \%$ ekor, rantai pemasaran II pedagang besar nilai share sekitar $2 \%$ ekor dan rantai pemasaran III para calo nilai share sekitar 1,5\%/ekor dari masing-masing rantai pemasaran. Rantai I adalah rantai panjang, dimana pemasaran dari pedagang kecil, hingga konsumen melewati 2 (dua) mata rantai, rantai pemasaran yang pendek adalah rantai III yaitu, pedagang kecil hingga konsumen tanpa melewati mata rantai yang lainnya.

Besarnya marjin pemasaran pada rantai III, sekitar $6 \%$ inilah pemasaran yang efektif dan effisien, keuntngan yang diperoleh oleh pedagang kecil sekitar Rp 55.094,25/ekor. Menurut Rusdiana, dkk (2011), bahwa penjualan termak kambing dan domba, di petani selalu lebih murah dibandingkan dengan pedagang kecil (Belantik desa dan pedagang besar), peterak tidak memperhitungkan ongkos dan tenaga kerja, dianggap sudah cukup memenuhi kebuthan pada saat dibutuhkan.

\section{PENUTUP}

Pasar Hewan Palasari merupakan salah satu pasar di Kabupaten Indramayu, yang mempunyai kegiatan pasar 2 kali dalam satu minggu. Jenis ternak yang diperdagangkan terdiri dari ternak domba dan kambing pada berbagai umur maupun jenis kelaminnya. Rantai pemasaran ternak tersebut mempunyai 3 (tiga) mata rantai hingga pada konsumen akhir. Sedangkan rantai pemasaran secara umum adalah rantai pemasaran I, dari pedagang kecil hingga konsumen. Pada masing-masing mata rantai memiliki margin pemasaran tersendiri, yaitu rantai pemasaran I, II dan III masing-masing menentukan nilai share dengan keuntungan yang berbeda, diperoleh rantai pemasaran I pedagnag kecil nilai share sekitar $2 \% /$ ekor, rantai pemasaran II pedagang besar nilai share sekitar $2 \% /$ ekor dan rantai pemasaran III para calo nilai share sekitar 1,5\%/ekor dari masing-masing rantai pemasaran. Besarnya marjin pemasaran domba secara keseluruhan mulai dari pedagang kecil hingga konsumen akhir adalah (Rp.2.428.813,8-Rp.2.300.000)=Rp.128.813.38/ekor pada ternak jantan atau shaare pemasaran sebesar Rp.2.428.813,8/Rp.2.300.000 x 100\% = 1.06\%. Pasar hewan Palasara mempunyai potensi untuk meningkatkan kesejahteraan masyarakat melalui kegiatan pasar yang sudah kondusif.

\section{DAFTAR PUSTAKA}

Abubakar, R. 2002. Ekonomi Pemasaran, Proyek dan Pengadaan Buku Ekonomi. PT Sumber Bahagia Offset. Jakarta. 
Coetzee, L. B. D. Montshwe and A. Jooste. 2005. The Marketing Of Livestock On Communal Lands In The Eastern Cope Province: Constraints, Challenges And Implications For The Extension Services S. Afr. Agric 34(1): 81-103.

Dinas Pertanian. 2014. Peternakan dan Kesehatan Hewan. Dinas Pertanian Kabupaten Indramayu Propinsi Jawa Barat.

Emhar. A. J. M. M. Aji, dan T. Agustina. 2014. Analisis Rantai Pasokan (Supply Chain) Daging Di Kabupaten Jember. Jurnal Berkah IImiah Pertanian 2(1): 1: 53.

Elizabeth.R. dan S. Rusdiana. 2011. Analisis ekonomi pendapatan usaha domba mendukung kesejahteraan petani. Prosiding Seminar Nasional Peternakan Berkelanjutan III, Fakultas Peternakan Universitas Padjadjaran, Bandung: 245-252.

Girei, A. A., B. Dire and B. H. Bello. 2013. Assesment of Cost and Returns of Cattle Marketing in Central Zone of Adamawa State, Nigeria. British J. Marketing Studies 1(1): 1-10.

Hangara. G. N.,M.Y. Teweldemedhin and I.B. Groenewold. 2012. Assessment of the Constraints of Cattle Supply Chain Management in Namibia: Case Study of Omahele Communal Farmers. African J. Agric. Research 7(4): 4876-4884.

Koesmara, Sudi Nurtini, dan I Gede Suparta Budisatria. 2013. Faktor-faktor yang Mempengaruhi Margin Pemasaran Sapi Potong dan Daging Sapi Di Kabupaten Aceh Besar. Jurnal Peternakan 39(1): 57-63,

Kotler, P., S. H. Ang, S. M. Leong, dan C. T. Tan. 2005. Manajemen Pemasaran: Sudut Pandang Asia Edisi Ketiga. PT Indeks. Jakarta.

Rusdiana, S.dan D. Priyanto. 2008. Analisis Pendapatan Usaha Ternak Domba Tradisional di Kabupaten Sukabumi. Pros. Seminar Nasional Teknologi Peternakan dan Veteriner. Bogor: 538-544.

Ramadhan. W. 2009. Analisis Marjin Pemasaran Sapi Potong di Kecamatan Singosari Kabupaten Malang Propinsi Jawa Timur. http://wahyugayo.blogspot.com. Diakses 15 Juli 2013.

Rusdiana. S. Rosganda, E. dan E. Romjali. 2013. Marjin Pemasaran Ternak Kambing dalam Pemenuhan Kebutuhan Konsumen: Analisis Ekonomi. Prosiding Seminar Nasional Prgram Studi Agribisnis Fakultas Pertanian Universitas Sebelas Maret: 331-337.

Soekartawi. 1993. Manajemen Pemasaran Hasil Pertanian, Teori dan Aplikasinya. CV. Rajawali. Jakarta.

Zivenge, E. and C. Karavina. 2012. Analysis of Factors Influencing Market Channel Access by Communal Horticulture Farmers in Chinamora District, Zimbabwe. Jurnal. Dev. Agric. Econ.p 4(1): 147-150. 